\title{
Time to restore body weight in adults and adolescents receiving cognitive behaviour therapy for anorexia nervosa
}

\author{
Simona Calugi $1^{i^{*}}$, Riccardo Dalle Grave ${ }^{1}$, Massimiliano Sartirana ${ }^{1}$ and Christopher G Fairburn ${ }^{2}$
}

\begin{abstract}
Background: The aim of the present study was to provide benchmark data on the duration of treatment required to restore body weight (to $\mathrm{BMI} \geq 18.5$ or a corresponding BMl centile) in adolescents and adults with anorexia nervosa treated with outpatient cognitive behaviour therapy.

Methods: Ninety-five participants (46 adolescents and 49 adults) were recruited from consecutive referrals to a specialist eating disorder clinic. Each was offered 40 sessions of enhanced cognitive behaviour therapy (CBT-E) over 40 weeks, the conventional length of this treatment.

Results: Twenty-nine (63.1\%) of the adolescents and 32 (65.3\%) of the adults completed all 40 sessions of treatment $(P=0.818)$. Significantly more adolescents reached the goal $B M l$ than adults $(65.3 \%$ vs. $36.5 \% ; P=0.003)$. The mean time required by the adolescents to restore body weight was about 15 weeks less than that for the adults (14.8 ( $\mathrm{SE}=1.7)$ weeks vs. $28.3(\mathrm{SE}=2.0)$ weeks, log-rank $=21.5, \mathrm{P}<0.001)$.

Conclusions: The findings indicate that adolescent patients receiving CBT-E are able to regain weight more successfully than adults and at a faster rate. If these findings are replicated and extend to eating disorder psychopathology, then their treatment could be shorter than that of adults.
\end{abstract}

Keywords: Anorexia nervosa, Treatment, Cognitive behaviour therapy, Eating disorder, Outcome

\section{Background}

Anorexia nervosa is considered one of the most difficult psychiatric disorders to treat [1]. Patients are often reluctant to accept treatment and among those who start a large subgroup has a poor outcome. Anorexia nervosa is also difficult to study [2-6] because is relatively rare, associated with medical risks, and may require a lengthy duration of treatment. These difficulties have led to the recommendation that new treatments should be extensively tested prior to being evaluated in randomized controlled trials [2-6].

Enhanced cognitive behaviour therapy (CBT-E) is a treatment for eating disorder psychopathology, irrespective of the eating disorder diagnosis [7-9]. There are data from randomized control trials supporting its use in

\footnotetext{
*Correspondence: si.calugi@gmail.com

'Department of Eating and Weight Disorder, Villa Garda Hospital, Via Montebaldo, 89, I-37016 Garda, VR, Italy

Full list of author information is available at the end of the article
}

bulimia nervosa, and the other non-underweight eating disorder presentations [10-12], and from randomized and observational studies of adolescents and adults with anorexia nervosa [13-17]. When used to treat patients who are underweight CBT-E generally involves about 40 sessions over 40 weeks [8] (i.e., about twice the length of CBT-E for patients who do not need to regain weight). This length of treatment is mainly to accommodate the time needed for weight regain. The optimal duration of treatment has not been established, and it may be shorter for adolescents than adults as it has been suggested that they are easier to treat [5].

\section{Purpose}

The aim of the present study was to obtain benchmark data on the duration of treatment required to restore body weight in adolescents and adults with anorexia nervosa treated with outpatient CBT-E. 


\section{Methods}

\section{Design}

A cohort of participants with anorexia nervosa was recruited from consecutive referrals to an eating disorder clinic. Eligible participants were offered 40 sessions of CBT-E over 40 weeks. This was the sole psychological intervention that they received. The study was approved by the local human subjects committee.

\section{Setting and participants}

The sample was recruited from consecutive referrals by family doctors and other clinicians to a well-established eating disorder clinic serving the Verona area of Italy. The patients were required to fulfill DSM-IV diagnostic criteria for anorexia nervosa [18] bar the amenorrhea criterion. In addition, for patients under 18 years, the patient's parents or legal guardians had to provide written informed consent to their participation after having received a full description of the study.

One hundred and fifty-two patients were screened, of whom 32 did not meet the inclusion criteria. Fifteen met the following exclusion criteria: (i) extremely underweight $(\mathrm{BMI}<14)(\mathrm{N}=1)$; (ii) marked medical complications (e.g., pronounced edema, severe electrolyte disturbance, hypoglycemia) $(\mathrm{N}=1)$; (iii) having received in the previous year a specialist treatment for anorexia nervosa $(\mathrm{N}=1)$; (iv) having a co-existing Axis 1 psychiatric disorder that precluded immediate eating disorder-focused treatment (e.g., psychosis or drug dependence, $\mathrm{N}=6$ ); and (v) not being available for the 40 week period of treatment $(\mathrm{N}=6)$.

The remaining 105 patients were offered CBT-E, of whom 95 accepted (90.5\%). A detailed description of the participants has been provided elsewhere $[13,14]$.

\section{The treatment}

CBT-E is a treatment for people with eating disorder psychopathology, irrespective of their eating disorder diagnosis. A detailed description of the treatment has been published [8]. In brief, CBT-E for patients who are underweight has three main steps. The goal of the first step is to help patients see the need for weight regain and decide to embark upon it. The goal of the second step is to help patients regain weight to a low-healthy level, and at the same time address their eating disorder psychopathology. In adults the goal BMI is between 19.0 and 19.9. In adolescents it is the equivalent BMI centile. In the third step, the goal is to help the patients maintain their new healthy weight. In the present study, CBT-E involved 40 one-to-one treatment sessions over 40 weeks. The 40 sessions were preceded by two preparatory sessions, and followed by a review session 20 weeks after completing treatment. The patients were considered "completers" if they attended to all the 40 sessions of treatment.
CBT-E for adults and adolescents is essentially the same. It differs in just one way. In adults significant others (friends, partner or parents) are only seen if it is thought likely that it will be beneficial and with the consent of the patient. This only applies in a minority of cases. When it happens, the role of the significant other is simply to support the implementation of the one-toone treatment. The same principles apply to the treatment of adolescent patients except that the parents are invariably involved given these patients' age and circumstances. In the present study, the great majority of sessions involved the adolescent patient alone. Parental involvement comprised a single one-hour assessment session in the first two weeks of treatment and eight 15minute sessions with the patient and parents together (immediately after an individual session). These occurred at weeks 1 to 4 and at weeks $8,12,20$, and 40 . The aim of the initial session with parents was to identify family factors liable to hinder the patient's attempts to change while the subsequent sessions were devoted to meal planning, the conduct of mealtimes and to the generation of solutions to problems that had emerged or were foreseeable. Additional sessions with the parents only took place if there were family crises, extreme difficulties at mealtimes or parental hostility towards the adolescent. Few such sessions were needed.

A single therapist treated each patient. There was no additional therapeutic input, either from physicians, dieticians or other health professionals, unless there was a specific indication (e.g., the management of medical complications or comorbid conditions). The sole additional input was assessment by a physician (Riccardo Dalle Grave, RDG) prior to starting treatment and, rarely, a reassessment if there were medical concerns (e.g., weight loss of over $0.5 \mathrm{~kg}$ in a week).

There were four therapists, all of whom were clinical psychologists. All the therapists had prior generic clinical experience and experience in treating patients with eating disorders, and each received six months initial training from Christopher G Fairburn (CGF) and RDG. Weekly supervision meetings were held throughout the study and were led by RDG. The therapists had sixmonthly booster workshops led by CGF. All the treatment sessions were recorded and these recordings were used as part of supervision to ensure that the treatment was well implemented.

\section{Assessment and measures}

\section{Body weight and body mass index}

Weight was measured using a beam balance scale and height was measured using a wall-mounted stadiometer. Participants were weighed wearing only underwear and without shoes. The body mass index (BMI) was determined for adults according to the standard formula of 
body weight measured in kilograms divided by height in meters squared. BMI centiles were calculated for adolescents using the Center for Disease Control and Prevention growth charts (www.cdc.gov/growthcharts). BMI and BMI centiles were measured each week throughout the duration of the treatment.

\section{Eating disorder features and general psychopathology}

The Italian version of the self-report Eating Disorder Examination Questionnaire (EDE-Q6.0) was used to measure eating disorder psychopathology. It was administered at baseline and at the end of treatment $[19,20]$.

The full version of the Symptom Checklist-90 (SCL90) was used to assess general psychopathology from which a Global Severity Index (GSI) was calculated $[21,22]$. The GSI was measured at baseline and at the end of treatment.

The Italian language version of the questionnaires has good psychometric properties $[20,22]$.

\section{Statistical analysis}

The demographic and baseline clinical characteristics of the adolescent and adult patients were compared using t-test, Mann-Whitney test or chi-square test, as appropriate.

A Kaplan-Meier estimate was used to evaluate differences on time to restore body weight, in the adult and adolescent patients respectively, during the 40 weeks of treatment. Two BMI thresholds were investigated; reaching a $\mathrm{BMI} \geq 18.5$ and reaching a $\mathrm{BMI} \geq 19.5$, or in the adolescents achieving the corresponding BMI centile [23]. A Cox regression model was used to analyze the independent baseline predictors (age, BMI, duration of illness, EDE-Q total score, SCL-90 GSI, number of binge eating and purging episodes) on time to reach $\mathrm{BMI} \geq$ 18.5 or corresponding BMI centile. Data on patients who did not reach these values were censored at 40 weeks. Dropouts for clinical reasons or for being admitted to inpatient treatment were censored at the date of interruption of the outpatient treatment. The proportional hazards assumption of the Cox regression model was tested using the log-log plot. With this method, a plot of the logarithm of the negative logarithm of the estimated survivor function against the logarithm of survival time yields parallel curves if the hazards are proportional across the adolescent and adult groups [24]. The log-log plot showed that the two curves looked approximately parallel, indicating that the proportional hazards assumption was met.

\section{Results}

The sample

The sample comprised 95 patients, 46 adolescents and 49 adults. Table 1 shows their baseline characteristics.
As would be expected, the adults had a longer duration of disorder than the adolescents and a greater proportion reported binge eating, self-induced vomiting, and laxative misuse.

\section{Treatment completion}

Sixty-one participants (64.2\%) completed the full 40 weeks of treatment (completers). The remainder (non-completers) either left the program prematurely or were referred for more intensive treatment. No significant differences were found between the completers and noncompleters on demographic (age, gender, marital status, occupation) and baseline clinical (duration of illness, weight, BMI, global EDE-Q, SCL-90 GSI) characteristics. The non-completion rate was similar in the adolescents and adults $\left(36.9 \%\right.$ vs. $34.7 \%$ respectively; $X^{2}(1,94)=$ $0.20, \mathrm{P}=0.839$ ). Eating disorder and general psychopathology significantly improved, as described in the two previous papers $[14,13]$, with there being no differences between the adults and adolescents at the end of treatment (mean global EDE-Q: $1.8(\mathrm{SD}=1.7)$ vs $1.5(\mathrm{SD}=$ 1.5), respectively $\mathrm{P}=0.365$; mean SCL-90 GSI: 0.9 ( $\mathrm{SD}=$ $0.7)$ vs $0.7(\mathrm{SD}=0.6)$, respectively $\mathrm{P}=0.139)$.

\section{Weight regain}

During the treatment, 32 of the adolescent patients (65.3\%) had reached a BMI $\geq 18.5$ or the corresponding centile compared with 19 of the adults $\left(36.5 \% ; \chi^{2}(1,94)=\right.$ 9.05, $\mathrm{P}=0.003)$. Among the adolescents and adults who reached their target BMI, no difference was found in the amount of weight regained $(5.8(\mathrm{SD}=3.7)$ vs $6.4(\mathrm{SD}=$ 3.0) $\mathrm{kg}$, respectively; $\mathrm{t}=0.61, \mathrm{P}=0.542$ ); however, the estimated mean time needed to achieve this weight goal was about 15 weeks less for the adolescents than for the adults $(14.8(\mathrm{SE}=1.7)$ v. $28.3(\mathrm{SE}=2.0)$ weeks, log rank $=21.5, \mathrm{P}<0.001$ ) (Figure 1). Among the patients who reached a $\mathrm{BMI} \geq 18.5$ or the corresponding centile, $96.6 \%$ of the adolescents and $80.0 \%$ of the adults maintained this weight at the end of treatment.

Similar results were found using a target BMI of 19.5 or more or the corresponding BMI centile [9]. Over half of the adolescents $(55.1 \%)$ and a third of the adults $(32.6 \%$; $\left.X^{2}(1,94)=3.95, P=0.047\right)$ achieved this BMI, and the time taken was about 11 weeks less for the adolescents than the adults $(25.1(\mathrm{SE}=2.1)$ v. 36.4 $(\mathrm{SE}=1.4)$ weeks, $\log$ rank $=23.0, \mathrm{P}<0.001)$.

A Cox regression model including demographic and baseline clinical characteristics showed that age and baseline BMI were the only two independent predictors of time required to reach a $\mathrm{BMI} \geq 18.5$ or corresponding BMI centile (Wald Chi-Square $=4.06, \mathrm{df}=1, \mathrm{P}=0.044$, $\mathrm{OR}=0.91$, 95\% CI 0.82-0.99; Wald Chi-Square $=13.35$, $\mathrm{df}=1, \mathrm{P}<0.001, \mathrm{OR}=1.85,95 \%$ CI $1.33-2.58$, respectively). Age was the only independent predictor of time 
Table 1 Baseline clinical characteristics in adolescent and adult patients with anorexia nervosa

\begin{tabular}{|c|c|c|c|}
\hline & Adolescents $(\mathrm{N}=46)$ & Adults $(\mathrm{N}=49)$ & Tests \\
\hline Age, years & $15.5(1.3)$ & $24.6(5.2)$ & $\mathrm{t}=11.78^{* * *}$ \\
\hline Gender, $\mathrm{n}(\%)$ female & $46(100 \%)$ & $48(98.0 \%)$ & $x^{2}=0.95$ \\
\hline Marital status, n (\%) & & & $x^{2}=4.95$ \\
\hline - single, never married & $46(100 \%)$ & $42(89.4 \%)$ & \\
\hline - married or living as such & 0 & $2(4.3 \%)$ & \\
\hline - separated or divorced & 0 & $3(6.4 \%)$ & \\
\hline Occupation, n (\%) & & & $x^{2}=35.41^{* * *}$ \\
\hline - full-time employment & 0 & $20(40.1 \%)$ & \\
\hline - student & $46(100 \%)$ & $22(44.9 \%)$ & \\
\hline - homeworker & 0 & $5(10.2 \%)$ & \\
\hline - unemployed & 0 & $2(4.1 \%)$ & \\
\hline Duration of eating disorder, years, median (range) & $0.5(0-5)$ & $3.0(0-17.0)$ & $Z=4.17^{* * *}$ \\
\hline \multicolumn{4}{|l|}{ Weight } \\
\hline - body weight (kg) & $40.0(5.7)$ & $41.6(6.0)$ & $t=1.33$ \\
\hline - body mass index $\left(\mathrm{kg} / \mathrm{m}^{2}\right)$ & - & $15.7(1.4)$ & \\
\hline - body mass index centile^ & $2.86(3.35)$ & - & \\
\hline - weight 95\% of that expected, n (\%) & $1(2.2)$ & - & \\
\hline \multicolumn{4}{|l|}{ Eating disorder psychopathology } \\
\hline - overall severity (global EDE-Q) & $2.79(1.5)$ & $2.87(1.5)$ & $t=0.26$ \\
\hline - global EDE-Q <1SD above the community mean", n(\%) & $18(41.9 \%)$ & $22(46.8 \%)$ & $x^{2}=0.32$ \\
\hline - dietary restraint (EDE-Q subscale) & $2.69(1.8)$ & $3.08(2.0)$ & $t=1.00$ \\
\hline - eating concern (EDE-Q subscale) & $2.58(1.5)$ & $2.68(1.6)$ & $t=0.31$ \\
\hline - shape concern (EDE-Q subscale) & $3.17(1.7)$ & $3.00(1.7)$ & $t=0.49$ \\
\hline - weight concern (EDE-Q subscale) & $2.75(1.6)$ & $2.69(1.5)$ & $t=0.19$ \\
\hline \multicolumn{4}{|l|}{ Eating disorder behaviour (EDE-Q) } \\
\hline - objective binge eating, $\mathrm{n}(\%)$ present & $2(4.3 \%)$ & $12(24.5 \%)$ & $x^{2}=7.66^{* *}$ \\
\hline if present, episodes/28 days, median(range) & $38.5(7-70)$ & $4.0(1-40)$ & \\
\hline - self-induced vomiting, n(\%) present & $1(2.2 \%)$ & $16(32.7 \%)$ & $x^{2}=15.00^{* * *}$ \\
\hline if present, episodes/28 days, median(range) & 120 & $9.5(1-60)$ & \\
\hline - laxative misuse, $\mathrm{n}(\%)$ present & $1(2.2 \%)$ & $8(16.3 \%)$ & $x^{2}=5.54^{*}$ \\
\hline if present, episodes/28 days, median(range) & 12 & $11.5(3-84)$ & \\
\hline General psychiatric features, GSI & $1.18(0.6)$ & $1.36(0.7)$ & $t=1.34$ \\
\hline
\end{tabular}

\#Global EDE-Q less than 1SD above community EDE-Q mean for young adult women [25] (i.e., <2.77).

$\wedge \mathrm{BMI}$ centile as 0.5 for those with a value $<1$.

EDE-Q - Eating Disorder Examination Questionnaire (version 6.0).

GSI - SCL-90 Global Severity Index.

${ }^{*} \mathrm{p}<0.05 ;{ }^{* *} \mathrm{p}<0.01 ;{ }^{* * *} \mathrm{p}<0.001$ adolescent vs. adult patients.

Data are shown as mean (SD) unless otherwise indicated.

required to reach a $\mathrm{BMI} \geq 19.5$ or corresponding $\mathrm{BMI}$ centile (Wald Chi-Square $=10.29, \mathrm{df}=1, \mathrm{P}=0.001, \mathrm{OR}=$ 0.80, 95\% CI 0.70-0.92).

\section{Discussion}

The aim of the study was to obtain benchmark data on the duration of treatment required to restore body weight in adolescents and adults with anorexia nervosa treated with outpatient CBT-E. There were two main findings. The first was that more adolescents than adults reached the two target BMIs. The second was that the adolescents did so at a faster rate: for example, the time taken to reach a BMI centile equivalent to 18,5 was about 15 weeks less than that for the adults. The time to reach the BMI $\geq 18.5$ and $\geq 19.5$ or the corresponding centile was associated with younger age and higher baseline BMI and younger age, respectively.

The present study had certain strengths. First, the two samples were large for studies of the treatment of anorexia 


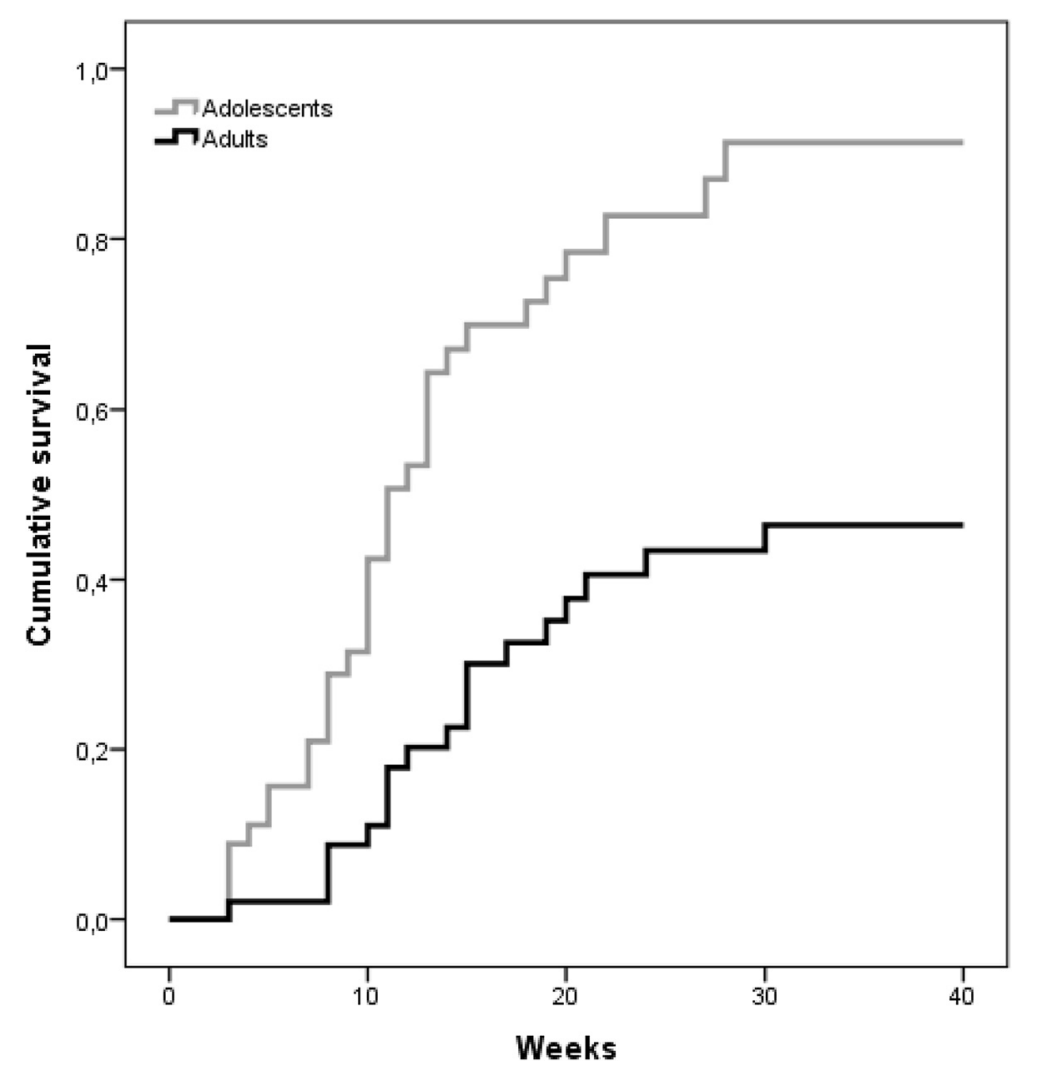

Figure 1 Survival curves predicting time to reach a BMI $\geq 18.5$ (or corresponding BMI centile) in adult and adolescent patients with anorexia nervosa.

nervosa; second, the patients were recruited from consecutive referrals to a long-established eating disorder clinic that provides the main clinical service for the local area. With regard to the baseline characteristics, our adult sample had a similar BMI to patients with anorexia nervosa described by the CBT outpatient study of Turner et al. [26], and a shorter average duration of eating disorder of patients with anorexia nervosa described by the CBT-E study of Byrne et al. [27]. No CBT or CBT-E studies on adolescents with anorexia nervosa are available for comparison. Our findings are therefore likely to be generalizable to clinical services elsewhere.

Third, and in contrast with most studies of the treatment of anorexia nervosa, the index treatment, CBT-E, was the patients' sole treatment with there being no other accompanying interventions. Lastly, the form of CBT-E used was essentially the same for the adolescents and adults. It is therefore likely that differences observed between the two age groups were genuine rather than being due to differences between the forms of CBT-E employed.

The study also had some limitations. First, the treatment was delivered in a single outpatient unit. Replication is therefore needed. Second, we focused on BMI as the target variable rather than eating disorder psychopathology.
We chose BMI as it is a key outcome variable in the treatment of anorexia nervosa and achieving a healthy BMI is one of the main determinants of length of treatment. A similar analysis focused on remission of eating disorder psychopathology would be of interest.

\section{Conclusions}

The findings indicate that adolescent patients receiving CBT-E are able to regain weight more successfully than adults and at a faster rate. If these findings are replicated and extend to eating disorder psychopathology, then their treatment could be shorter than that of adults.

\section{Competing interests}

The authors declare that they have no competing interests.

\section{Authors' contributions}

SC supervised and participated in data collection, performed data analysis and interpretation, and drafted the manuscript. RDG coordinated the research trial, participated in recruitment, supervised the intervention, and participated in manuscript preparation and writing. MS participated in recruitment, provided the intervention and participated in manuscript preparation and writing. CGF designed and coordinated the research trial, supervised the intervention, supervised data analysis and interpretation, and made substantial contributions to the manuscript. All authors read and approved the final manuscript. 


\section{Funding}

CGF is supported by a Principal Research Fellowship from the Wellcome Trust (046386).

\section{Author details}

1Department of Eating and Weight Disorder, Villa Garda Hospital, Via Montebaldo, 89, I-37016 Garda, VR, Italy. ${ }^{2}$ Department of Psychiatry, Oxford University, Warneford Hospital, Oxford OX3 7JX, UK.

Received: 4 February 2015 Accepted: 20 April 2015

Published online: 28 May 2015

\section{References}

1. Halmi KA, Agras WS, Crow S, Mitchell J, Wilson GT, Bryson SW, et al. Predictors of treatment acceptance and completion in anorexia nervosa: Implications for future study designs. Arch Gen Psychiatry. 2005;62(7):776-81. doi:10.1001/ archpsyc.62.7.776.

2. Agras WS, Brandt HA, Bulik CM, Dolan-Sewell R, Fairburn CG, Halmi KA, et al. Report of the National Institutes of Health workshop on overcoming barriers to treatment research in anorexia nervosa. Int J Eat Disord. 2004;35(4):509-21. doi:10.1002/eat.10261.

3. Bulik CM, Berkman ND, Brownley KA, Sedway JA, Lohr KN. Anorexia nervosa treatment: A systematic review of randomized controlled trials. Int J Eat Disord. 2007:40(4):310-20. doi:10.1002/eat.20367.

4. Fairburn CG. Evidence-based treatment of anorexia nervosa. Int J Eat Disord. 2005;37(Suppl):S26-30. discussion S41-2. doi:10.1002/eat.20112.

5. Halmi KA. The perplexities of conducting randomized, double-blind, placebo-controlled treatment trials in anorexia nervosa patients. Am J Psychiatry. 2008;165(10):1227-8. doi:10.1176/appi.ajp.2008.08060957.

6. Lock J, Brandt H, Woodside B, Agras S, Halmi WK, Johnson C, et al. Challenges in conducting a multi-site randomized clinical trial comparing treatments for adolescent anorexia nervosa. Int J Eat Disord. 2012;45(2):202-13. doi:10.1002/ eat.20923.

7. Fairburn CG, Cooper Z, Shafran R. Cognitive behaviour therapy for eating disorders: A "transdiagnostic" theory and treatment. Behav Res Ther. 2003:41:509-28.

8. Fairburn CG, Cooper Z, Shafran R, Bohn K, Hawker DM, Murphy R, et al. Enhanced cognitive behavior therapy for eating disorders: The core protocol. In: Fairburn CG, editor. Cognitive Behavior Therapy and Eating Disorders. New York: Guilford Press; 2008. p. 45-193.

9. Fairburn CG. Cognitive behavior therapy and eating disorders. New York: Guilford Press; 2008.

10. Fairburn CG, Cooper Z, Doll HA, O'Connor ME, Bohn K, Hawker DM, et al. Transdiagnostic cognitive-behavioral therapy for patients with eating disorders: A two-site trial with 60-week follow-up. Am J Psychiatry. 2009;166:311-9.

11. Poulsen S, Lunn S, Daniel SI, Folke S, Mathiesen BB, Katznelson H, et al. A randomized controlled trial of psychoanalytic psychotherapy or cognitivebehavioral therapy for bulimia nervosa. Am J Psychiatry. 2014;171(1):109-16. doi:10.1176/appi.ajp.2013.12121511.

12. Wonderlich SA, Peterson CB, Crosby RD, Smith TL, Klein MH, Mitchell JE, et al. A randomized controlled comparison of integrative cognitive-affective therapy (ICAT) and enhanced cognitive-behavioral therapy (CBT-E) for bulimia nervosa. Psychol Med. 2014;44(3):543-53. doi:10.1017/ S0033291713001098

13. Dalle Grave R, Calugi S, Doll HA, Fairburn CG. Enhanced cognitive behaviour therapy for adolescents with anorexia nervosa: An alternative to family therapy? Behav Res Ther. 2013;51(1):R9-R12. doi:10.1016/j.brat.2012.09.008.

14. Fairburn CG, Cooper Z, Doll HA, O'Connor ME, Palmer RL, Dalle GR. Enhanced cognitive behaviour therapy for adults with anorexia nervosa: A UK-Italy study. Behav Res Ther. 2013;51(1):R2-8. doi:10.1016/ j.brat.2012.09.010.

15. Zipfel S, Wild B, Gross G, Friederich HC, Teufel M, Schellberg D, et al. Focal psychodynamic therapy, cognitive behaviour therapy, and optimised treatment as usual in outpatients with anorexia nervosa (ANTOP study): Randomised controlled trial. Lancet. 2014;383(9912):127-37. doi:10.1016/ S0140-6736(13)61746-8.

16. Dalle Grave R, Calugi S, Conti M, Doll H, Fairburn CG. Inpatient cognitive behaviour therapy for anorexia nervosa: A randomized controlled trial. Psychother Psychosom. 2013;82(6):390-8.

17. Dalle Grave R, Calugi S, El Ghoch M, Conti M, Fairburn CG. Inpatient cognitive behavior therapy for adolescents with anorexia nervosa: immediate and longer-term effects. Front Psychiat. 2014;5:14. doi:10.3389/ fpsyt.2014.00014.

18. American Psychiatric Association. Diagnostic and Statistical Manual of Mental Disorders. 4th ed. Washington, DC: American Psychiatric Association; 2000.

19. Fairburn CG, Beglin SJ. Eating Disorder Examination Questionnaire (EDE-Q 6.0). In: Fairburn CG, editor. Cognitive Behavior Therapy and Eating Disorders. New York: Guilford Press; 2008. p. 309-13.

20. Dalle Grave R, Calugi S. La Terapia cognitivo comportamentale dei disturbi dell'alimentazione. In: Fairburn CG, editor. Versione Italiana dell'Eating Disorder Examination Questionnaire (EDE-Q 6.0). Eclipsi. Firenze ed., 2010. p. 401-7.

21. Derogatis LR. The SCL-90 manual: Scoring, administration and procedures for the SCL-90. Clinical Psychometric Research: Baltimore; 1977.

22. Prunas A, Sarno I, Preti E, Madeddu F, Perugini M. Psychometric properties of the Italian version of the SCL-90-R: a study on a large community sample. Eur Psychiatry. 2012;27(8):591-7. doi:10.1016/j.eurpsy.2010.12.006.

23. Cole TJ, Flegal KM, Nicholls D, Jackson AA. Body mass index cut offs to define thinness in children and adolescents: international survey. BMJ. 2007;335(7612):194. doi:10.1136/bmj.39238.399444.55.

24. Kleinbaum DG. Survival Analysis: A Self-Learning Text. 1996.

25. Hay P, Rodgers B, Owen C. Eating Disorder Examination Questionnaire (EDE-Q): norms for young adult women. Behaviour Research and Therapy. 2006;44:53-62.

26. Turner H, Marshall E, Stopa L, Waller G. Cognitive-behavioural therapy for outpatients with eating disorders: Effectiveness for a transdiagnostic group in a routine clinical setting. Behav Res Ther. 2015;68:70-5. doi:10.1016/j. brat.2015.03.001.

27. Byrne SM, Fursland A, Allen KL, Watson $H$. The effectiveness of enhanced cognitive behavioural therapy for eating disorders: An open trial. Behav Res Ther 2011;49(4):219-26.

\section{Submit your next manuscript to BioMed Central and take full advantage of:}

- Convenient online submission

- Thorough peer review

- No space constraints or color figure charges

- Immediate publication on acceptance

- Inclusion in PubMed, CAS, Scopus and Google Scholar

- Research which is freely available for redistribution

Submit your manuscript at www.biomedcentral.com/submit 